\title{
A definitive allosauroid (Dinosauria; Theropoda) from the Lower Cretaceous of East Sussex
}

\author{
Darren Naish
}

\begin{abstract}
NAISH, D. 2003. A definitive allosauroid (Dinosauria; Theropoda) from the Lower Cretaceous of East Sussex. Proceedings of the Geologists' Association, 114, 319-326. A partial proximal tibia (estimated total length of tibia $550 \mathrm{~mm}$ ) from a large theropod was discovered in the Samuel Beckles collection of Hastings Museum and Art Gallery, East Sussex. It was probably collected from the Hastings Group of the Wealden Supergroup. Derived character states show that it can be referred to the Allosauroidea but it is more robust than are the tibiae of Neovenator salerii, the only well-known Wealden allosauroid, and the two differ in the morphology of the fibular crest, cnemial crest and proximal articular condyles. The Hastings specimen, therefore, probably belongs to another Wealden allosauroid, possibly Becklespinax altispinax (a taxon based on dorsal vertebrae). Large theropod material from the Hastings Group has been reported before but generally lacks characters that allow it to be identified beyond Tetanurae.
\end{abstract}

School of Earth and Environmental Sciences, University of Portsmouth, Burnaby Road, Portsmouth PO1 3QL, UK

\section{INTRODUCTION}

Theropod dinosaurs have proved diverse in the Wealden Supergroup (Lower Cretaceous: BerriasianAptian) of southern England and include both largeand small-bodied taxa, many of which have highly convoluted systematic histories (Naish, 1999a, 2002; Naish et al., 2001). Recent work shows that the smaller Wealden theropods include compsognathids (Naish, 2002; Naish et al., in press), oviraptorosaurs (Naish \& Martill, 2002), dromaeosaurids (Howse \& Milner, 1993; Norell \& Makovicky, 1997) and birds (Harrison \& Walker, 1973), while larger forms include spinosauroids (Charig \& Milner 1997; Martill \& Hutt, 1996), allosauroids (Owen, 1855, 1857; Hutt et al., 1989, 1996) and the basal tyrannosauroid Eotyrannus lengi (Hutt et al., 2001). A probable new taxon of large theropod from the Wessex Formation of the Isle of Wight is under study by the author and S. Hutt.

Though articulated remains are rare, allosauroid theropods are represented in the Wealden Supergroup of both the English mainland and the Isle of Wight (Allosauroidea is used here in the sense of Holtz (2000) to include Sinraptoridae, Allosaurus, Neovenator and Carcharodontosauridae). Due to its fragmentary nature and a confused nomenclature, no attempt has yet been made to collate and describe this material, though the holotypes of Valdoraptor oweni (BMNH R2559) and Becklespinax altispinax (BMNH R1828) have received some recent attention (Olshevsky, 1991; Molnar, 1992; Naish, 1999a). While these taxa are assumed to be members of the Allosauroidea, it has yet to be demonstrated that they exhibit the derived characters of the clade and the discrepancy in length between metatarsals II and III of $V$. oweni suggest that it may not be an allosauroid. The only associated Wealden allosauroid skeleton (BMNH R10001/MIWG.6348) is the holotype of Neovenator salerii. While $N$. salerii has been monographed by Hutt (1999), this remains unpublished and Hutt et al. (1989, 1996) and Naish et al. (2001) remain the only widely available source of $N$. salerii illustrations.

The presence in $N$. salerii of paired dorsolateral ridges on the nasals, an antorbital fossa that excavates the ventrolateral part of the nasal and a pubic boot which is triangular in ventral view show that it is an allosauroid but within this clade its affinities require further study. Based on the shared derived characters of five premaxillary teeth, prezygapophyses on the distal caudals that extend more than one half (but less than one) centrum length and other characters, Hutt et al. (1996) and Holtz (2000) suggested that $N$. salerii was closest to Allosaurus (both taxa thus forming a monophyletic Allosauridae). N. salerii also, however, exhibits several features seen in carcharodontosaurids (including an ischial foot, broad obturator notch and pleurocoelous caudal dorsal vertebrae) leading Harris (1998), Hutt (1999) and Naish et al. (2001) to favour an affinity with the carcharodontosaurids.

Three isolated tetanuran theropod tibiae have been reported from the Wealden Supergroup. MIWG.5137 from the Wessex Formation is probably referable to the compsognathid Aristosuchus (Naish et al., 2001) but BMNH R186 (also from the Wessex Formation) and BMNH R9385 (from the Hastings Group) have 


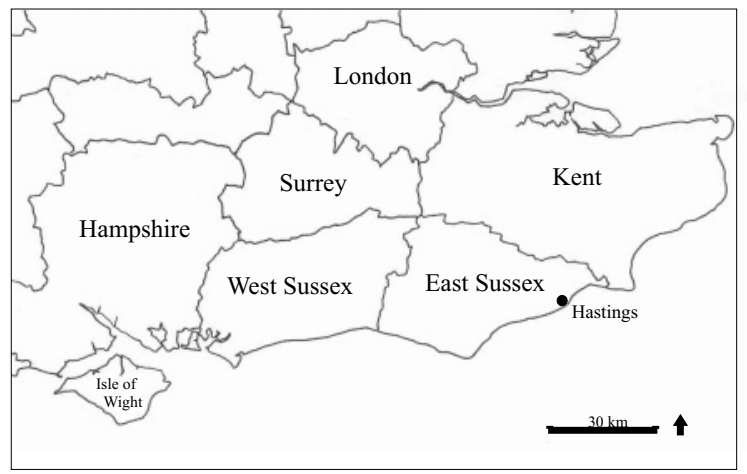

Fig. 1. Map of southeast England. HASMG G.378 was probably collected from the Hastings Group in the Hastings region, East Sussex.

proved more enigmatic (Naish, 1999b). Theropod tibiae are not only characteristic; they also reveal a wealth of features that usually allow them to be identified to specific clades and sometimes even to a genus, as demonstrated by Mateus \& Antunes (2000) and Chure (2001).

The proximal end of a large right theropod tibia (HASMG G.378) was discovered in the Samuel Husbands Beckles collection of Hastings Museum and Art Gallery, Hastings, East Sussex, southern England. This specimen has been mentioned previously (as 'HASTM GG98') by Benton \& Spencer (1995). Beckles (1814-1890) collected his larger dinosaurian specimens mainly from the Hastings Group and is well known for the Iguanodon tracks and skeletal material that he collected while living in St Leonards (now part of Hastings), East Sussex (Fig. 1) (Woodhams, 1990). The specimen is presumed to have been collected from the Hastings Group (BerriasianValanginian) and from the Hastings area, but from which formation and precise location remains unknown (Fig. 2). Other material from large theropods has been reported from the Hastings Group before but, excepting BMNH R1828, is undiagnostic and has been assigned to the Middle Jurassic genus Megalosaurus (Benton \& Spencer, 1995). Thecospondylus horneri from the Hastings Group of Southborough, Kent (based on the internal cast of a sacrum, specimen BMNH R291), has sometimes been regarded as a theropod (e.g. Steel, 1970) but lacks informative features and cannot be reliably identified (Naish et al., 2001). A partial tibia from an indeterminate mediumsized Hastings Group tetanuran was described by Naish (1999b).

Institutional abbreviations BMNH, Natural History Museum, London; HASMG, Hastings Museum and Art Gallery, Hastings, East Sussex; MIWG, Museum of Isle of Wight Geology/Dinosaur Isle Visitor Centre, Sandown, Isle of Wight.

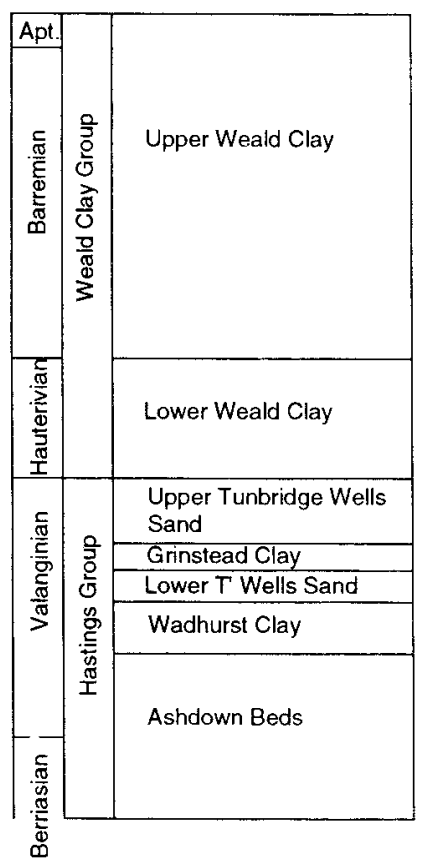

Fig. 2. Simplified stratigraphic succession of the Wealden of the Weald. HASMG G.378 was probably collected from the Hastings Group but from which formation is unknown. After Cook (1997).

\section{SYSTEMATIC PALAEONTOLOGY}

Dinosauria Owen, 1842

Saurischia Seeley, 1888

Theropoda Marsh, 1881

Tetanurae Gauthier, 1986

Allosauroidea Marsh, 1879

Gen. et sp. indet.

\section{Specimen}

Incomplete proximal right tibia HASMG G.378 (Figs 3-4).

\section{Locality}

Uncertain but presumably Hastings, East Sussex. The absence of evidence for beach roll suggests that the specimen was collected from an inland site.

\section{Geological horizon and age}

Uncertain but presumably Hastings Group. Lower Cretaceous: Berriasian-Valanginian. 


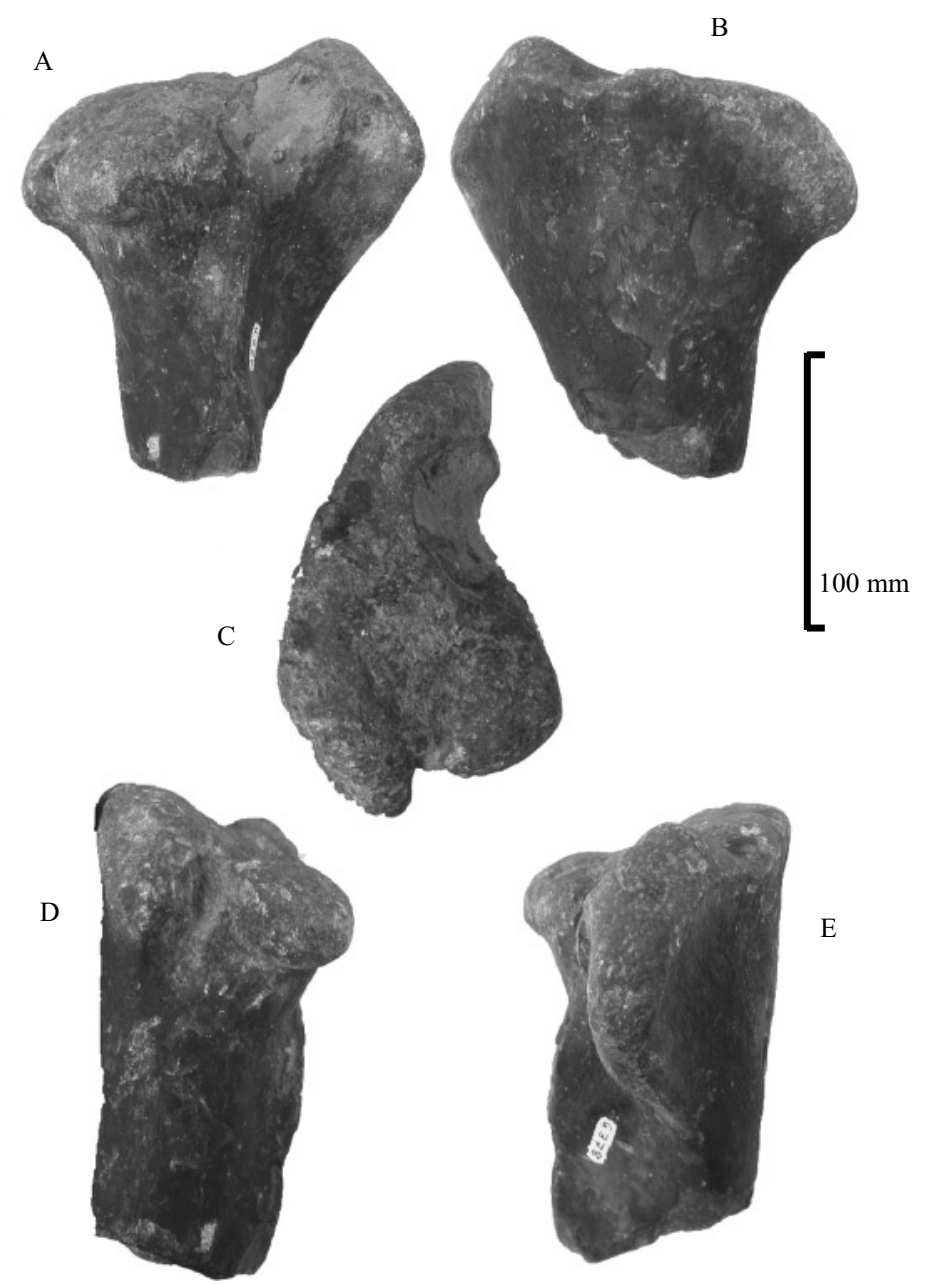

Fig. 3. HASMG G.378 from the Hastings Group of the Hastings region: (A) lateral view; (B) medial view; (C) proximal view; (D) caudal view; (E) cranial view.

\section{DESCRIPTION}

The specimen is the proximal end of a large right theropod tibia that appears to end $70-50 \%$ down the proximodistal length of the fibular crest (based on comparison with complete allosauroid tibiae). The specimen is undistorted and, while most of the original bone surface is preserved, some of it, especially that round the broken distal end and that on the medial surface of the cnemial crest, has broken away. The total preserved length is $190 \mathrm{~mm}$, the craniocaudal length of the proximal end is $180 \mathrm{~mm}$ and the maximum width of the proximal end is $100 \mathrm{~mm}$. The maximum width of the distal end is $75 \mathrm{~mm}$. Comparison with complete allosauroid tibiae suggests an original total length of approximately $550 \mathrm{~mm}$.

The cnemial crest has a squared-off lateral profile and projects dorsocranially such that its apex is notably taller than the proximal articular surface. It is similar in profile to that of Allosaurus (Gilmore, 1920). In proximal view, the cnemial crest curves laterally and the proximal articular surface appears as long craniocaudally compared to its width as it does in the tibiae of Allosaurus and N. salerii (Figs 3C, 5C). The incisura tibialis is located on the dorsolateral part of the cnemial crest and in proximal view forms a distinct crescentic concavity. At the cranial edge of the incisura tibialis is a caudodistally directed ridge (labelled 'accessory ridge' in Fig 5A) and that is joined proximally to the apex of the cnemial crest. The same structure is present on the holotype tibia of $N$. salerii (Hutt, 1999). The medial surface of the cnemial crest is gently convex.

The proximal condyles are well developed and differ in size and form from each other. The lateral condyle is rounded caudally and has the form of a dorsoventrally compressed sphere. There is a poorly developed craniolateral projection on the lateral condyle's cranial 


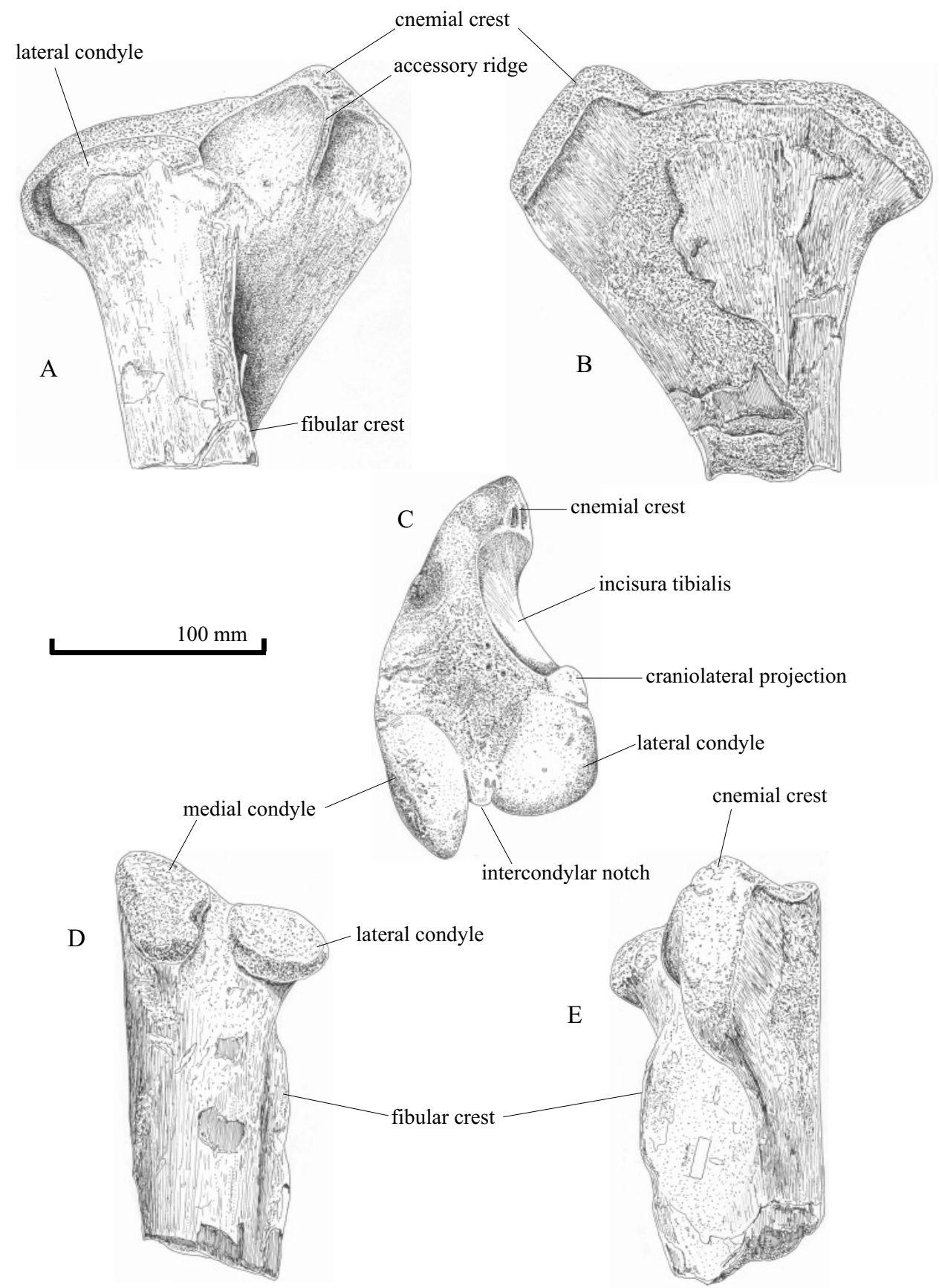

Fig. 4. Illustrations of proximal right tibia HASMG G.378: (A) lateral view; (B) medial view; (C) proximal view; (D) caudal view; (E) cranial view.

edge (Fig. 3C). It is worn and may have formed a sharper process in life. This structure is well preserved in the holotype of N. salerii (Hutt, 1999) and is well known for Allosaurus (Gilmore, 1920). Molnar et al. (1990), referring to this structure as a 'small process of the tibia extending parallel to the head of the fibula', regarded it as one of several features shared by Allosaurus and tyrannosaurids. While abundant evidence now indicates that Allosaurus and tyrannosaurids do not form a clade (e.g. Holtz, 1994, 2000), this feature is 


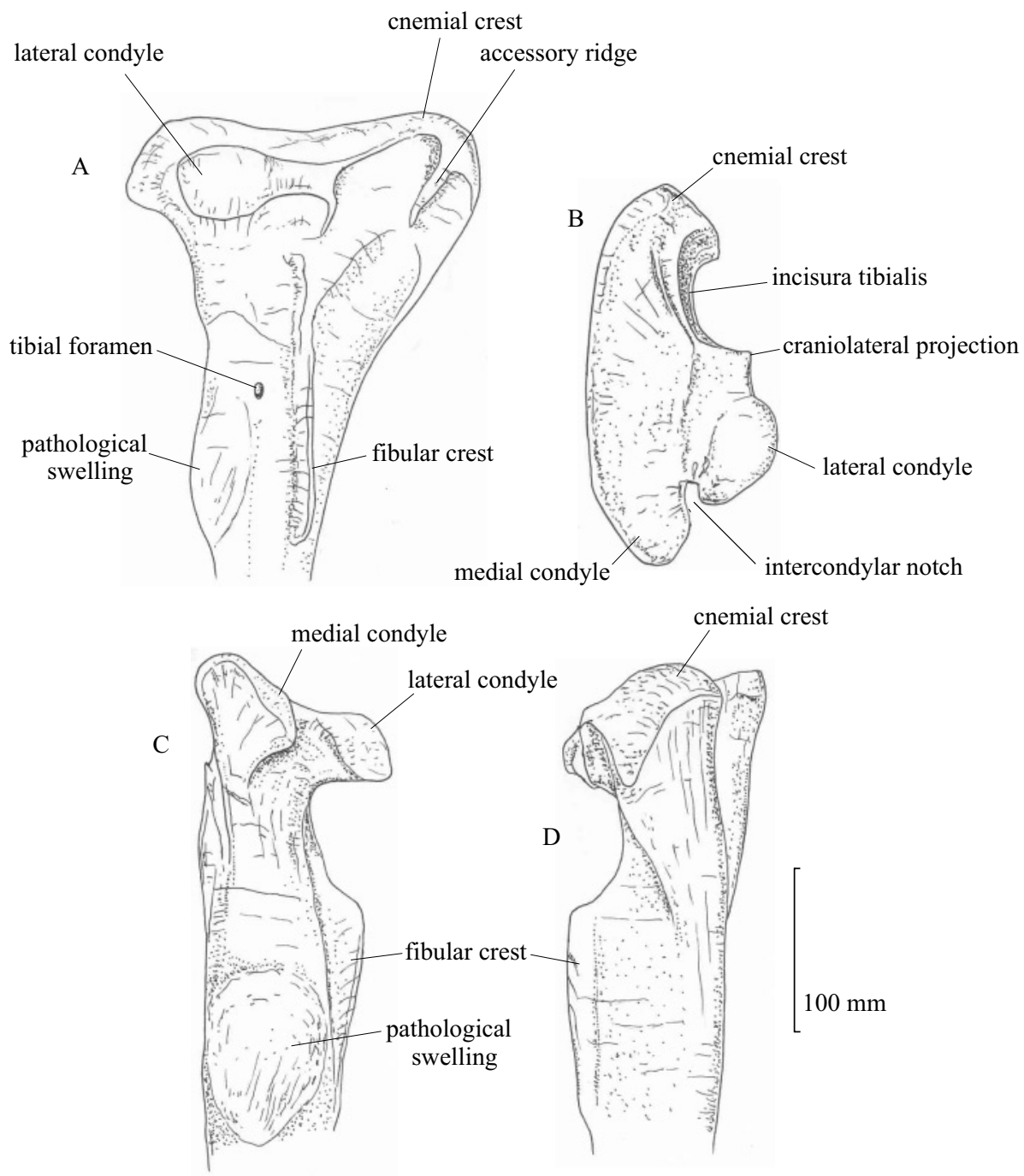

Fig. 5. Proximal left tibia (reversed) of BMNH R10001/MIWG.6348, holotype of Neovenator salerii, from the Wessex Formation of the Isle of Wight: (A) lateral view; (B) proximal view; (C) caudal view; (D) cranial view. After Hutt (1999).

in any case apparent (but in a less developed condition) elsewhere in the Theropoda (Azuma \& Currie, 2000; Chure, 2001). The medial condyle in HASMG G.378 is tall and narrow and with its long axis slanting distolaterally. Caudally, the condyles are separated by a distinct intercondylar notch.

The fibular crest is a low ridge that, at its most proximal extent, is just distal to the ventral surface of the lateral condyle. It, therefore, extends further proximally than do the fibular crests of both Allosaurus and $N$. salerii. In HASMG G.378 the fibular crest's ridge is broken, meaning that the exact shape of the crest cannot be determined. No foramina can be seen demonstrating that, as is apparently typical of noncoelurosaurs (Naish, 1999b), the tibial foramen was located distally. In caudal view, the proximal articular surface slopes toward the lateral side and the medial condyle is therefore higher than the lateral condyle at its apex. A flexor fossa on the proximocaudal surface of the shaft is not present. In lateral view the medial condyle descends further distally than the lateral condyle.

\section{IDENTIFICATION OF HASMG G.378}

The specimen is unmistakably from a theropod as no other animals have a cnemial crest and proximal articular surface of this form. The specimen is similar to the proximal tibiae of both Allosaurus (Gilmore, 1920; Madsen, 1976; Chure, 2001) and N. salerii (Hutt et al., 1996; Hutt, 1999), though as discussed below 
there are also a number of differences. The following four features were examined as they have proved informative in previous studies.

\section{Presence of notch between the proximal articular condyles}

The presence of a pronounced notch between the proximal articular condyles indicates that HASMG G.378 is not from a spinosauroid or more basal theropod as in these forms the caudal intercondylar notch is shallow (Chure, 2001). The morphology of the notch in both Allosaurus and Neovenator is comparable to that of HASMG G.378 (Figs 3C, 5C). It should be noted that, assuming inclusion of Sinraptoridae within Allosauroidea (Holtz, 2000), a shallow notch is probably the primitive character state for Allosauroidea given this condition in Sinraptor dongi (Currie \& Zhao, 1994).

\section{Presence and extent of incisura tibialis}

The presence in HASMG G.378 of a well developed incisura tibialis (=fibular fossa of Sereno et al., 1996) is indicative of allosauroid identity as this structure is poorly developed or absent in more basal theropods. Conversely, in coelurosaurs the incisura tibialis occupies more of the lateral side of the cnemial crest (not the medial side, as reported by Harris (1998), Holtz (2000) and Azuma \& Currie (2000)) than it does in allosauroids and more basal theropods. Sereno et al. (1996) were the first to employ this character (their character 63) and Holtz (2000) and Azuma \& Currie (2000) later quantified it by regarding an incisura tibialis occupying more than $66 \%$ of the lateral surface of the proximal tibia as the coelurosaurian character state. In HASMG G.378 the incisura tibialis does not exhibit the extensive coelurosaurian condition, being instead comparable in size to that of Allosaurus and N. salerii (Figs 3C, 5C).

\section{Relative craniocaudal elongation of the proximal end}

The relative craniocaudal elongation of the proximal end of HASMG G.378 relative to its width also suggests allosauroid identity. In Allosaurus, the width:length ratio of the proximal tibia is between $1: 1.7$ and $1: 1.9$ and in $N$. salerii it is $1: 2$. In HASMG G.378 the ratio is $1: 1.8$. The proximal articular surface of the tibia in Sinraptor dongi and Fukuiraptor kitadaniensis is less elongate craniocaudally than that of Allosaurus, N. salerii and HASMG G.378 with a value of 1:1.4 (Currie \& Zhao, 1994; Azuma \& Currie, 2000) and non-tetanurans appear to exhibit even lower values (e.g. 1:1.3 in Elaphrosaurus (Chure, 2001)). The condition in HASMG G.378, therefore, indicates that it is more derived within the Allosauroidea than are $F$. kitadaniensis and the sinraptorids. At least some neoceratosaurs (e.g. Ceratosaurus and Quilmesaurus with a value of 1:2) have width:length ratios as high as those of derived allosauroids however (Coria, 2001). This feature appears to have phylogenetic value but requires further sampling and evaluation.

\section{Form of lateral condyle}

HASMG G.378 clearly does not exhibit the proportionally small, cranially located lateral condyle proposed by Russell \& Dong (1994) as a derived character of some coelurosaurian clades. Azuma \& Currie (2000) identified three different morphologies present in the theropod lateral condyle. The presence on the lateral condyle of a smoothly convex lateral margin was regarded as the primitive character state and is present in Herrerasaurus and Sinraptor. Allosauroids other than sinraptorids however (Acrocanthosaurus, Allosaurus and Fukuiraptor) were coded as possessing 'conspicuous waisting between body of condyle and main body of tibia [with] small, triangular prominence anteriorly, sometimes with low ridge extending to crista fibularis' (Azuma \& Currie, 2000, their character 108). A third character state - presence of conspicuous waisting between the body of the condyle and the main body of the tibia and of a deep cranial trough - was identified by Azuma \& Currie (2000) as present in ornithomimids and tyrannosaurids. HASMG G.378 exhibits the second state for this character, as does $N$. salerii and other non-sinraptorid allosauroids.

\section{COMPARISON WITH OTHER WEALDEN ALLOSAUROIDS}

Identification of HASMG G.378 as an allosauroid means that comparison is restricted to only three named taxa: Valdoraptor oweni (Lydekker, 1889), Becklespinax altispinax (Paul, 1988) and Neovenator salerii Hutt et al., 1996. As discussed above, while $N$. salerii is an unambiguous allosauroid, $V$. oweni is only tentatively referred to this group. While tibiae are unknown for $V$. oweni and B. altispinax, well-preserved tibiae are known for $N$. salerii (Hutt et al., 1996; Hutt, 1999). These differ from HASMG G.378 in being more gracile and in having a mediolaterally broader cnemial crest, a lateral condyle that projects further laterally and a fibular crest that does not extend as far proximally as it does in HASMG G.378 (Fig. 5). While the left tibia of $N$. salerii is pathological, the pathology (a bulge-like swelling on the caudal surface of the shaft approximately one-third down the shaft) is restricted in area and does not affect the proximal articular area.

The differences noted between the $N$. salerii holotype and HASMG G.378 suggest that the Hastings specimen is not referable to $N$. salerii but belonged to a related allosauroid with more robust limb bones. $B$. altispinax, named for three caudal dorsal vertebrae 
figured by Owen (1855) and discussed by Owen (1857) and Huene (1923), is regarded here as an allosauroid (pending further work). The depth of the centra and both craniocaudal and mediolateral dimensions of the neural spines of B. altispinax imply that it was a robust animal that would have had tibiae of less gracile morphology than those seen in $N$. salerii. It is, therefore, tempting to suggest that HASMG G.378 might represent a $B$. altispinax tibia. Until better material of $B$. altispinax is known, however, this hypothesis remains untestable.

\section{CONCLUSIONS}

- HASMG G.378 is a proximal right tibia from a large theropod.

- The presence of an incisura tibialis and deep notch between the proximal condyles show that HASMG G.378 is a tetanuran.

- The detailed morphology and character states present in the proximal theropod tibia show that HASMG G.378 is an allosauroid more closely re- lated to Allosaurus and Neovenator salerii than to sinraptorids and other basal allosauroids.

- Important differences between HASMG G.378 and the tibiae of $N$. salerii indicate that HASMG G.378 is not referable to this taxon and probably represents a different form of derived allosauroid with more robust limb bones. It may belong to Becklespinax altispinax but as this taxon is based only on dorsal vertebrae this is presently untestable.

\section{ACKNOWLEDGEMENTS}

I thank Cathy Walling (Hastings Museum and Art Gallery), Sandra Chapman (Natural History Museum, London) and Martin Munt (Dinosaur Isle Visitor Centre, Sandown) for access to specimens in their care, Steve Hutt for comments and access to his thesis, Bob Loveridge for assistance with Figure 3, Dave Martill for reading the manuscript at 7:45 in the morning, and an anonymous reviewer for providing comments that improved the manuscript. Martin Simpson kindly assisted in research and brought HASMG G.378 to my attention.

\section{REFERENCES}

Azuma, Y. \& Currie, P.J. 2000. A new carnosaur (Dinosauria: Theropoda) from the Lower Cretaceous of Japan. Canadian Journal of Earth Sciences, 37, 1735-1753.

Benton, M.J. \& Spencer, P.S. 1995. Fossil Reptiles of Great Britain. Chapman \& Hall, London.

Charig, A.J. \& Milner, A.C. 1997. Baryonyx walkeri, a fish-eating dinosaur from the Wealden of Surrey. Bulletin of the Natural History Museum, 53, 11-70.

Chure, D.J. 2001. The second record of the African theropod Elaphrosaurus (Dinosauria, Ceratosauria) from the Western Hemisphere. Neues Jahrbuch fur Geologie und Paläontologie, Monatshefte, 2001, 565-576.

Cook, E. 1997. Sedimentology and vertebrate taphonomy of bone-bearing facies from the Clockhouse Rock Store (Weald Clay, late Hauterivian), Capel, Surrey, UK. Proceedings of the Geologists' Association, 108, 49-56.

Coria, R.A. 2001. New theropod from the Late Cretaceous of Patagonia. In (Tanke, D.H. \& Carpenter, K.; eds) Mesozoic Vertebrate Life. Indiana University Press, Bloomington \& Indianapolis, 3-9.

Currie, P.J. \& Zhao, X. 1994. A new carnosaur (Dinosauria, Theropoda) from the Jurassic of Xinjiang, People's Republic of China. Canadian Journal of Earth Sciences, 30, 2037-2081.

Gauthier, J. 1986. Saurischian monophyly and the origin of birds. Memoirs of the California Academy of Science, 8, $1-55$.

Gilmore, C.W. 1920. Osteology of the carnivorous Dinosauria in the United States National Museum, with special reference to the genera Antrodemus (Allosaurus) and Ceratosaurus. Bulletin of the United States National Museum, 110, 1-154.

Harris, J.D. 1998. A renanalysis of Acrocanthosaurus atokensis, its phylogenetic status, and paleobiogeographic implications, based on a new specimen from Texas. New Mexico Bulletin of Natural History and Science, 13, 1-75.
Harrison, C.J.O. \& Walker, C.A. 1973. Wyleyia: a new bird humerus from the Lower Cretaceous of England. Palaeontology, 16, 721-728.

Holtz, T.R. 1994. The phylogenetic position of the Tyrannosauridae: implications for theropod systematics. Journal of Palaeontology, 68, 1100-1117.

Holtz, T.R. 2000 (for 1998). A new phylogeny of the carnivorous dinosaurs. Gaia, 15, 5-61.

Howse, S.C.B. \& Milner, A.R. 1993. Ornithodesmus - a maniraptoran theropod dinosaur from the Lower Cretaceous of the Isle of Wight, England. Palaeontology, 36, 425-437.

Huene, F. 1923. von Carnivorous Saurischia in Europe since the Triassic. Bulletin of the Geological Society of America, 34, 449-458.

Hutt, S. 1999. Neovenator salerii: a new theropod dinosaur from the Wealden of the Isle of Wight, its status and significance for theropod evolution. MPhil thesis, University of Portsmouth..

Hutt, S., Simmonds, K. \& Hullman, G. 1989. Predatory dinosaurs from the Isle of Wight. Proceedings of the Isle of Wight Natural History \& Archaeology Society, 9, 137-146.

Hutt, S., Martill, D.M. \& Barker, M.J. 1996. The first European allosaurid dinosaur (Lower Cretaceous, Wealden Group, England). Neues Jahrbuch fur Geologie und Paläontologie, Monatshefte, 1996, 635-644.

Hutt, S., Naish, D., Martill, D.M., Barker, M.J. \& Newbery, P. 2001. A preliminary account of a new tyrannosauroid theropod from the Wessex Formation (Early Cretaceous) of southern England. Cretaceous Research, 22, 227-242.

Lydekker, R. 1889. Note on some points in the nomenclature of fossil reptiles and amphibians, with preliminary notices of two new species. Geological Magazine (Decade 3), 6 , 325-326.

Madsen, J.H. 1976. Allosaurus fragilis: a revised osteology. Utah Geological and Mineral Survey Bulletin, 109, $1-163$. 
Marsh, O.C. 1879. Principal characteristics of American Jurassic dinosaurs. Part. II. American Journal of Science, Series 3, 17, 86-92.

Marsh, O.C. 1881. Principal characteristics of American Jurassic dinosaurs. Pt. V. American Journal of Science, Series 3, 21, 417-423.

Martill, D.M. \& Hutt, S. 1996. Possible baryonychid dinosaur teeth from the Wessex Formation (Lower Cretaceous, Barremian) of the Isle of Wight, England. Proceedings of the Geologists' Association, 197, 81-84.

Mateus, O. \& Antunes, M.T. 2000. Torvosaurus sp. (Dinosauria: Theropoda) in the Late Jurassic of Portugal. In Livro de Resumos do I Congresso Ibérico de Paleontologia / XVI Jornadas de la Sociedad Española de Paleontología, 115-117.

Molnar, R.E. 1992. Problematic Theropoda: "carnosaurs". In (Weishampel, D.B., Dodson, P. \& Osmólska, H.; eds) The Dinosauria. University of California Press, Berkeley, 306-317.

Molnar, R.E., Kurzanov, S.M. \& Dong, Z. 1990. Carnosauria. In (Weishampel, D.B., Dodson, P. \& Osmólska, H.; eds) The Dinosauria. University of California Press, Berkeley, 169-209.

Naish, D. 1999a. Studies on Wealden Group Theropods - an investigation into the historical taxonomy and phylogenetic affinities of new and previously neglected specimens. MPhil thesis, University of Portsmouth..

Naish, D. 1999b. Theropod dinosaur diversity and palaeobiology in the Wealden Group (Early Cretaceous) of England: evidence from a previously undescribed tibia. Geologie en Mijnbouw, 78, 367-373.

Naish, D. 2002. The historical taxonomy of the Lower Cretaceous theropods (Dinosauria) Calamospondylus and Aristosuchus from the Isle of Wight. Proceedings of the Geologists' Association, 113, 153-163.

Naish, D. \& Martill, D.M. 2002. A reappraisal of Thecocoelurus daviesi (Dinosauria: Theropoda) from the Early Cretaceous of the Isle of Wight. Proceedings of the Geologists' Association, 113, 23-30.

Naish, D., Hutt, S. \& Martill, D.M. 2001. Saurischian dinosaurs 2: Theropods. In (Martill, D.M. \& Naish, D.; eds) Dinosaurs of the Isle of Wight. The Palaeontological Association, London, 242-309.

Naish, D., Martill, D.M. \& Frey, E. in press. A new theropod dinosaur from the Santana Formation (?Albian, Early Cretaceous), N.E. Brazil and palaeoecological aspects of the Santana dinosaur fauna. Historical Biology.

Norell, M.A. \& Makovicky, P.J. 1997. Important features of the dromaeosaur skeleton: information from a new specimen. American Museum Novitates, 3215, 1-28.

Olshevsky, G. 1991. Revision of the Parainfraclass Archosauria Cope, 1869, Excluding the Advanced Crocodylia. Publications Requiring Research (privately printed), San Diego.

Owen, R. 1842. Report on British fossil reptiles. Report of the British Association for the Advancement of Science, 11, 60-204.

Owen, R. 1855. Monograph on the fossil Reptilia of the Wealden and Purbeck Formations. Part II. Dinosauria. Palaeontographical Society Monograph, 14 (Part II), 1-54.

Owen, R. 1857. Monograph on the fossil Reptilia of the Wealden and Purbeck Formations. Part III. Dinosauria (Megalosaurus). (Wealden). Palaeontographical Society Monograph, 14 (Part III), 1-26.

Paul, G.S. 1988. Predatory Dinosaurs of the World. Simon \& Schuster, New York.

Russell, D.A. \& Dong, Z.-M. 1994. The affinities of a new theropod from the Alxa Desert, Inner Mongolia, People's Republic of China. Canadian Journal of Earth Sciences, 30, 2107-2127.

Seeley, H.G. 1888. The classification of the Dinosauria. Report of the British Association for the Advancement of Science, 1887, 698-699.

Sereno, P.C., Dutheil, D.B., Iarochene, M., Larsson, H.C.E., Lyon, G.H., Magwene, P.M., Sidor, C.A., Varricchio, D.J. \& Wilson, J.A. 1996. Predatory dinosaurs from the Sahara and Late Cretaceous faunal differentiation. Science, 272, 986-991.

Steel, R. 1970. Encyclopedia of Paleoherpetology, Part 14: Saurischia. Gustav Fischer Verlag, Stuttgart.

Woodhams, K. 1990. On the trail of Iguanodon. Proceedings of the Croyden natural History and Scientific Society, 18, $45-58$.

Manuscript received 11 February 2003; revised typescript accepted 27 June 2003 